\title{
An Examination of the Day-of-The-Week Trading Patterns of Individual and Institutional Investors
}

Article in SSRN Electronic Journal · September 2012

DOI: $10.2139 /$ ssrn.2140244

CITATIONS

0

2 authors, including:

\section{Joel N Morse}

University of Baltimore

23 PUBLICATIONS 331 CITATIONS

SEE PROFILE
READS

19

Some of the authors of this publication are also working on these related projects: 


\title{
GLOBAL BUSINESS \& FINANCE REVIEW
}

\section{Day-of-the-Week Trading Patterns of Individual and Institutional Investors}

\author{
Joel N. Morse ${ }^{\mathrm{a}}$, Hoang Nguyen ${ }^{\mathrm{b}}$, and Hao M. Quach ${ }^{\mathrm{c}}$ \\ ${ }^{a}$ Professor of Finance at Merrick School of Business, University of Baltimore, Baltimore, MD, USA. \\ ${ }^{b}$ Associate Professor of Finance at Merrick School of Business, University of Baltimore, Baltimore, MD, USA. \\ ${ }^{c}$ Lecturer in Finance at Lincoln Business School, University of Lincoln, UK
}

\section{A B S T R A C T}

This study examines the day-of-the-week trading patterns of individual and institutional investors. Consistent with previous evidence, we find an increase in the proportion of Monday trading volume attributable to individual investors relative to other days of the week. However, we document that this increase results from a reduction in trading by institutional investors, rather than from an absolute increase in trading by individual investors. In fact, the absolute trading volume by individual investors is significantly lower on Monday than on any other weekday. We also document that the degree of day-of-the-week effect varies with the quality and dissemination of public information proxied by the market capitalization of each company.

Keywords: Day of the week trading patterns, Individual Investors, Institutional Investors, Trading Information

\section{I . Introduction}

The interactions among different types of investors determine the trading volume, return volatility, transaction costs and the price of a stock. The trading behavior of different types of investors might not be the same, due to differences in wealth, information and liquidity. Among investors, the two groups that attract the most researcher and practitioner interest are individual investors and institutional investors. Given the increasing importance of institutions in the U.S. equity markets, understanding the different trading patterns of the two groups can improve our knowledge of stock price dynamics.

The authors thank an anonymous referee, as well as Professor Honghui Chen for helpful comments and suggestions.

$\uparrow$ Corresponding Author - Joel N. Morse

the Merrick School of Business, University of Baltimore, Baltimore,

MD 21201-5779, jmorse@ubalt.edu, (410) 837-4989
Empirical evidence on stock returns, trading volume, return volatility and transaction costs for different days of the week is extensive. Monday returns are documented to be generally negative [French (1980), Gibbons and Hess (1981), Keim and Stambaugh (1984), Lakonishok and Levi (1982), Rogalski (1984)] and Monday trading volume is significantly lower than other days of the week [Jain and Joh (1988), Lakonishok and Maberly (1990)]. In addition, the adverse selection cost of trading appears to be highest on Monday [Foster and Viswanathan (1993)]. Return volatility over the weekend is significantly lower than the volatility over other days of the week [French and Roll (1986)]. Recently, Venezia and Shapira (2007) discuss how weekends affect both amateur and professional investors. Subsequent to the weekend, individuals are prone to increase both buying and selling, whereas institutional investors tend towards the opposite behavior. Akyol (2013) finds that as the length of non-trading periods such as weekends or holidays lengthens, an upward price effect in the morning 
session before the non-trading period, as well as a downward price effect in the morning session after the non-trading interval are both accentuated. Interestingly, he attributes this to uncertainty that increases in the length of the non-trading situation. Chen and Singhal (2003) suggest that short sellers could be responsible for the day of the week effect since they reverse short positions before a weekend, and re-establish them after a weekend. Berument and Kiymaz (2001) do not differentiate between retail and institutional participants, but do note that Monday returns are lower than on other days, and the volatility of returns are higher on Fridays. Recent work on non-US market by Dicle and Levendis (2012) who study 51 markets, and Linden et al (2006) who examine 18 stock exchanges both found evidence for the day-of-the-week effect.

One potential explanation for the above day-of-the-week anomalies could be the differential behavior of different groups of investors. A number of empirical studies have examined trading by either institutional investors or individual investors over the week. On one side, Lakonishok and Maberly (1990), and Abraham and Ikenberry (1994) use odd-lot sales on the New York Stock Exchange (NYSE) as a percentage of NYSE volume to proxy for individual investor's activities, and document an increase in the proportion of odd-lot trades on Monday. They propose that individual traders are the cause of the day-of-the-week irregularity. On the other side, Sias and Starks (1995) use institutional ownership data to proxy for the presence of institutional investors and find that the day-of-the-week effect is stronger in stocks having more institutional ownership. Using more recent data, Chan et al (2004) also examine the Monday effect conditioned on institutional ownership, and find that this phenomenon becomes weaker in stock markets characterized by a high percentage of institutional holdings.

It should be noted that these studies focus on the day-of-the-week variations in trading within only one group of investors at a time. Thus, in this study, we attempt to fill the gap in the literature by simultaneously examining the trading behavior of both institutional and individual investors, which will allow us to have a better understanding about their relative trading activities and roles in the day-of-the-week anomaly.

Using methodologies developed by Lee (1992), we examine the trading activity on a sample of 300 NYSE stocks during the year 2000.2) We classify each trade as either large

\footnotetext{
2) The reviewer suggested the importance of expanding the timeframe of the data beyond this single year. We agree, and take this as a suggestion for future research.
}

or small, based on its dollar trading volume. All the transactions with dollar volume of less than $\$ 10,000$ are classified as small trades, and those of more than or equal to $\$ 10,000$ are classified as large trades. The small trades and large trades are used to proxy for the trading activity by individual investors and by institutional investors, respectively. This approach yields new insights into the variation in trading volumes throughout the week.

Specifically, we find that the fraction of trades executed by individual investors is higher on Monday than on any other days of the week. Moreover, we document that individual investors trade less frequently on Monday than on other days. Further analysis of this apparent paradox shows that the greater fraction of trades by individual investors on Monday is a result of a significant reduction in trades by institutional investors on that day. The evidence is consistent with the hypothesis suggested by Sias and Starks (1995) that the diurnal variation in trading activity by the institutional investors is likely to be the cause for the observed day-of-the-week effect.

The results of this study are related to the theoretical work of Foster and Viswanathan (1990). In their model, informed traders accumulate private information through the weekend, when public information is not produced at the normal weekday rate. As a result, uninformed traders are at a larger disadvantage at the beginning of the week. Therefore, uninformed traders who have discretion over the timing of trade will delay their transactions until later in the week. The results from this study indicate that a proportion of both individual investors and institutional investors try to avoid costly Monday. Also, the reduction in absolute trading activities by both types of investors varies with the quality and dissemination of public information proxied by the market capitalization of each company.

\section{Data and Methodology}

\section{A. Data}

We examine trading activity for a random sample of 300 common stocks (those with a CRSP code of either 10 or 11) listed on the NYSE. We use two databases in our analysis. The first one is the TAQ database, from which we extract trading information. The second data source is the Center for Research in Security Prices (CRSP), from which we gather general information about the sample of securities. After matching stocks from the two databases, we keep only 
Table 1. Descriptive Statistics

Our sample includes 300 randomly selected common stocks (those with a CRSP code of either 10 or 11) listed on the NYSE on the year 2000. We require that selected stocks have an end-of- year price between $\$ 5.00$ and $\$ 100.00$ and have at least 12 trades per days to ensure that the sample has sufficient liquidity. This table reports descriptive statistics for our sample in terms of number of trades, market capitalization and average stock prices.

\begin{tabular}{llll}
\hline Characteristics & $\begin{array}{l}\text { Mean } \\
\text { (Median) }\end{array}$ & $\begin{array}{l}\text { First Quartile } \\
\text { (Third Quartile) }\end{array}$ & $\begin{array}{l}\text { Minimum } \\
\text { (Maximum) }\end{array}$ \\
\hline Number of Trades & 69,326 & 15,585 & 4,256 \\
& $(24,131)$ & $(65,838)$ & $(2,969,473)$ \\
Market Capitalization at Beginning & 8,422 & 457.5 & 102.7 \\
(In Millions of Dollars) & $(1,950)$ & $(7,595)$ & $(45,532)$ \\
Average Price at the Beginning & 30.80 & 18.35 & 5.21 \\
& $(24.47)$ & $(34.71)$ & $(99.51)$ \\
\hline
\end{tabular}

those equity securities that have a beginning-of-year price and an end-of-year price between $\$ 5$ and $\$ 100$ per share. The exclusion of stocks with a price less than five dollars ensures that liquidity is not affected by the relatively high percentage bid-ask spread caused by low price, while stocks with price greater than $\$ 100$ are excluded because they are less likely to have small trades associated with individual investors. Finally, we require that stocks in the sample have at least an average of 12 trades per day to ensure enough observations for analysis. From the resulting sample, we randomly choose 300 stocks to use in our analysis. The descriptive statistics in Table 1 show that the mean (median) market capitalization of the 300 sample firms is 8,422 $(1,950)$ million dollars and the average (median) number of trades for the 300 stocks is $69,326(24,131)$.

\section{B. Methodology}

This study uses a method developed by Lee (1992) to classify each trade as large or small based on its dollar volume. All transactions of $\$ 10,000$ or less are classified as small trades, and the remainder is classified as large trade $\mathrm{s}^{3}$ ). Although individual investors may place orders valued greater than $\$ 10,000$, it is unlikely that any institutional investors will trade at dollar volume less than $\$ 10,000$. Lee (1992) justifies the use of the $\$ 10,000$ threshold for small trades since it ensures small trades will have little institutional activity yet still contain enough observations. Using this criterion, about $48 \%$ of all the trades are classified as small trades. The small trades are used to proxy for the trading activity by individual investors, while the large trades are

\footnotetext{
3) To check the sensitivity of the results to the threshold of small trades, a threshold of $\$ 20,000$ for small trades is also used. The results from the two different thresholds are qualitatively similar.
}

used to proxy for the trading activity by institutional investors.

Each day, the numbers (volume and dollar volume) of small and large trades are obtained for each stock. To make them comparable across stocks, these numbers are further deflated by the total aggregated numbers (volumes dollar volume) of small and large trades of the stock during the year. The deflated measure on each day represents the small (large) trades on that day as a proportion of annual small (large) trades in year 2000. Mathematically, let

$$
y_{i t}^{z}=\frac{T_{i t}^{z}}{\text { Year }_{i}^{z}}
$$

where $y_{i t}^{z}$ is the scaled measure of number of trades (volume, dollar volume) of size $\mathrm{z}$ (small or large) of stock $\mathrm{i}$ during period $\mathrm{t}, T_{i t}^{z}$ is the total number of trades (volume, dollar volume) of size $z$ (small or large) of stock $i$ on day t. $\operatorname{Year}_{i}^{z}$ is the total number of trades (volume, dollar volume) of size $\mathrm{z}$ of stock $\mathrm{i}$ during the year 2000 .

For each stock, the following statistical model is estimated for both individual and institutional trades.4)

$$
y_{i t}=\mu_{i}+\sum_{j=2}^{5} D_{j} \cdot \mu_{i, j}+\varepsilon_{i t}
$$

Where is the measure of trading activity for stock $\mathrm{i}$ on day $\mathrm{t}, D_{j}(\mathrm{j}=2,3,4,5)$ is the day of the week, from Tuesday through Friday. Therefore, $\mu_{i, j}$ will capture the average

\footnotetext{
4) This regression model is first used by French (1980) to investigate the variation in stock return among days of the week and become popular in this field.
} 
trading activity for stock $\mathrm{i}$ on Monday while $i, j$ will capture the difference in trading between other weekday and Monday. To reduce the impact of heteroscedesticity and serial-correlation in residuals, we employ generalized methods of moments (GMM) and Newey-West (1987) correction for residual serial correlation in our regression model. We use an asymptotic normal distribution to test the significance of coefficient on each day-of-the-week dummy variable.

Based on estimation on individual stock, we report the average of coefficients for each day-of-the-week dummy variable, as well as the number of positive coefficients. These results are reported for the entire sample of 300 stocks and each capitalization-subsample of 100 stocks.

\section{Empirical Evidence}

\section{A. Variation in the Proportion of Trades by Individuals}

Table 2 provides evidence on day-of-the-week variation in the proportion of trades by individual investors. Panel A of Table 2 reports results based on the proportion of volume ordered by individual traders. For the entire sample, the proportion of individual trades on Monday is $0.823 \%$, $0.785 \%, 0.692 \%$, and $0.581 \%$ higher than that on Tuesday, Wednesday, Thursday, and Friday, respectively; and all coefficients are significant at 0.001 level. This suggests that there is significant variation in day-of-the-week trading activity by individual investors.

A similar conclusion can be drawn from other panels. Panel B of Table 2 shows that the day-of-the-week variation in dollar trading volume is significant. For the entire sample, the dollar volume made by individual investors on Monday is $0.731 \%$ higher than that on Tuesday, $0.613 \%$ more than that on Wednesday, $0.583 \%$ more than that on Thursday and $0.461 \%$ more than that on Friday. Similarly, Panel C indicates that the proportion of number of trades by individuals on Monday higher than other trading day by $1.268 \%, 0.924 \%, 1.151 \%$ and $0.804 \%$, respectively. These results are consistent with the results of Lakonishok and Maberly (1990), who document a relative increase in trading activities by individual investors.

Another finding on Table 2 is that the increase in proportional trading on Monday by individuals is largest for the lowest capitalization sub-sample. In terms of proportion of trading volume, for small-capitalization stocks, Monday trading by individuals is more than $1 \%$ higher than on any other trading days, while for the medium and large stock sub-samples, the numbers are all less than $0.8 \%$. A similar tendency can be observed for dollar volume and number of trades by individuals in Panel B and C.

Table 2 documents a significant drop in trading by individuals on other week days compared to Monday. That phenomenon could result from greater participation by individual investors in the equity market on Monday, or from a reduction in trading activities by other traders, namely institutions, on Monday.

To clarify the above issue, in the following sections, we examine the absolute participation of individual investors and by institutions independently across days of the week. For brevity, below only the results based on trading volume are reported.5)

\section{B. Variation in Individual Trades}

Table 3 provides further details on the day-of-the-week variation in the individual trading volume. For the whole sample, the coefficient of $0.0169 \%$ means that Tuesday trading volume by individual traders is higher than that on Monday by an average of $0.0169 \%$ of the total individual trading volume of the year 2000. Also, trading volume by individual on Monday is lower when comparing with Wednesday and Thursday numbers by about $0.0140 \%$ and $0.0121 \%$ of the total individual trading volume of the year; all numbers are statistically significant at $1 \%$ level. The difference between Friday and Monday is $0.0073 \%$ and marginally significant at $10 \%$ level. Out of 300 stocks, there are about 200 positive coefficients for each day.

\footnotetext{
5) The results based on dollar volume and number of trades is quantitatively and qualitatively similar to those based on trading
} volume, and are available upon request. 
Table 2. Day-of-the-Week Variation in the Proportion of Trades by Individuals

The proportion of individual trades on a given day is calculated by adding all the individual trades (volume, dollar volume) together across all the stocks, then divided by all the trades (volume, dollar volume) of all the stocks on that day. This proportion is then analyzed for the day-of-the-week variation.

$$
y_{t}=\mu+\sum_{i=2}^{5} D_{i} \cdot \mu_{i}+\varepsilon_{t}
$$

where is the error term, $y_{t}$ is the dependent variable calculated as defined above, and the $D_{i}$ is the day of the week dummy. $* * *, * * *$ are the significant level of $1 \%, 5 \%$ and $10 \%$, respectively.

Panel A: Variation in Proportion of Volume by Individual Traders

\begin{tabular}{lllll}
\hline $\begin{array}{l}\text { Day-of-the-Week } \\
\text { Tests }\end{array}$ & $\begin{array}{l}\text { Lowest Market } \\
\text { Capitalization }\end{array}$ & $\begin{array}{l}\text { Medium } \\
\text { Capitalization }\end{array}$ & $\begin{array}{l}\text { Mighest } \\
\text { Capitalization }\end{array}$ & Market \\
\hline Tuesday & $-1.723 * * *$ & $-0.633 * *$ & $-0.795 * * *$ & $-0.823 * * *$ \\
Wednesday & $-1.435 * * *$ & $-0.662 * *$ & -0.634 & $-0.785 * * *$ \\
Thursday & $-1.480 * * *$ & $-0.432 * *$ & $-0.537 * *$ & $-0.692 * * *$ \\
Friday & $-0.634 *$ & -0.351 & $-0.620 *$ & $-0.581 * * *$ \\
\hline
\end{tabular}

Panel B: Variation in Proportion of Dollar Volume by Individual Traders

\begin{tabular}{lllll}
\hline $\begin{array}{l}\text { Day-of-the-Week } \\
\text { Tests }\end{array}$ & $\begin{array}{l}\text { Lowest Market } \\
\text { Capitalization }\end{array}$ & $\begin{array}{l}\text { Medium } \\
\text { Capitalization }\end{array}$ & $\begin{array}{l}\text { Market } \\
\text { Capitalization }\end{array}$ & Market \\
\hline Tuesday & $-2.451 * * *$ & $-0.568 * * *$ & $-0.682 * * *$ & $-0.731 * * *$ \\
Wednesday & $-1.8652 * * *$ & $-0.452 * *$ & $-0.235 * * *$ & $-0.613 * * *$ \\
Thursday & $-1.536 * * *$ & $-0.520 * * *$ & $-0.591 * * *$ & $-0.583 * * *$ \\
Friday & -0.385 & -0.153 & $-0.437 * * *$ & $-0.461 * * *$ \\
\hline
\end{tabular}

Panel C: Variation in Proportion of Number of Trades by Individual Traders

\begin{tabular}{lllll}
\hline $\begin{array}{l}\text { Day-of-the-Week } \\
\text { Tests }\end{array}$ & $\begin{array}{l}\text { Lowest Market } \\
\text { Capitalization }\end{array}$ & $\begin{array}{l}\text { Medium } \\
\text { Capitalization }\end{array}$ & $\begin{array}{l}\text { Market } \\
\text { Capitalization }\end{array}$ & Market \\
\hline Tuesday & $-2.102 * * *$ & $-0.721 * * *$ & $-1.289 * * *$ & $-1.268 * * *$ \\
Wednesday & $-1.587 * * *$ & $-0.652 * *$ & $-0.952 * * *$ & $-0.924 * * *$ \\
Thursday & $-1.052 * * *$ & $-0.829 * *$ & $-1.537 * * *$ & $-1.151 * * *$ \\
Friday & $-0.551 *$ & -0.231 & $-1.025 * * *$ & $-0.804 * * *$ \\
\hline
\end{tabular}

Table 3. Day-of-the-Week Variation in Trading Volume by Individual

For each trading day, the volume of individual trades on each stock is scaled by the 2000 total volume of individual trades on that stock. The following regression equation is estimated for each stock using GMM.

$$
y_{i t}=\mu_{i}+\sum_{j=2}^{5} D_{j} \cdot \mu_{i, j}+\varepsilon_{i t}
$$

where $\varepsilon_{i t}$ is the error term for stock i, $y_{i t}$ is the scaled individual trading volume on each day $\mathrm{t}$, and the $D_{j}$ is the

\begin{tabular}{|c|c|c|c|c|c|}
\hline Day-of-the-Week & & $\begin{array}{l}\text { Lowest Market } \\
\text { Capitalization }\end{array}$ & $\begin{array}{l}\text { Medium } \\
\text { Market } \\
\text { Capitalization }\end{array}$ & $\begin{array}{l}\text { Highest } \\
\text { Market } \\
\text { Capitalization }\end{array}$ & All 300 stocks \\
\hline \multirow[t]{2}{*}{ Tuesday Coefficient } & Average $\left(* 10^{4}\right)$ & $1.235 * * *$ & $1.965^{* * *}$ & $1.862 * * *$ & $1.687 * * *$ \\
\hline & Positive Number & 74 & 68 & 85 & 227 \\
\hline Wednesday Coefficient & Average $\left(* 10^{4}\right)$ & $1.258 * * *$ & $1.102 * * *$ & $1.852 * * *$ & $1.404 * * *$ \\
\hline
\end{tabular}
day of the week dummy. $* * *, * *, *$ are the significant level of $1 \%, 5 \%$ and $10 \%$, respectively. 


\begin{tabular}{lllll|l} 
& Positive Number & 51 & 78 & 95 & 224 \\
\hline Thursday Coefficient & Average $\left(* 10^{4}\right)$ & $0.689^{* *}$ & $1.981^{* * *}$ & $0.957^{* * *}$ & $1.209^{* * *}$ \\
& Positive Number & 62 & 59 & 74 & 195 \\
\hline Friday Coefficient & Average $\left(* 10^{4}\right)$ & $0.892^{*}$ & $1.287^{* *}$ & 0.012 & $0.730^{*}$ \\
& Positive Number & 51 & 40 & 38 & 129 \\
\hline
\end{tabular}

When we look at the three capitalization sub-samples we see a similar tendency. For the subsample of the highest market capitalization stocks, the average of the Tuesday coefficient is $0.0186 \%$, which indicates that individual trading volume is higher on Tuesday than on Monday, by $0.0186 \%$ of the annual individual trading volume. The number of positive coefficients for this group of stocks is 85 . For the other two size groups, Tuesday trading is higher than Monday level for $0.0197 \%, 0.0186 \%$, respectively. Also, the number of positive coefficients is 74 and 68, respectively. On Wednesday and Thursday, the coefficients are all positive and significant at $1 \%$ level. For the three subsamples, individual trading volumes seems to reduce the least for the Lowest market capitalization group as coefficient for this groups is smaller than the other two in most cases.

The results of this section suggest that individual traders are less active on Monday in absolute terms. This finding indicates that the greater proportion of trading accounted for by individual traders on Monday (documented in Table 2) is not caused by an increases in trading by individual on Monday but by an even greater reduction in institutional trading on Monday. The next section examines the day-of-the-week variation in institutional trading volume.

\section{Variation in Institutional Trades}

Table 4 reports the day-of-the-week variation in trading volume by institutions. It is evident that all coefficient show positive and significant and this implies that institutions also trade more on other days than on Monday. For the whole 300 -stock sample, Monday trading volume by institutions is lower than that on Tuesday, Wednesday, Thursday and Friday by $0.0374 \%, 0.0339 \%, 0.0468 \%$, and $0.0149 \%$, respectively. The coefficient of $0.0374 \%$ on Tuesday suggests that trading volume by institutions is higher than that on Monday by an average of $0.0374 \%$ of the total institutional trading volume of the year 2000. The number of positive coefficients for those 4 days is above 200 . When we examine the three capitalization subsamples, we see a similar picture; all coefficients are positive and statistically significant. This suggests that the variation in trading by institutions prevails for all market capitalization segments.

Another important finding is that, the coefficients viewed in Table 4 are significantly larger than corresponding number in Table 3. It means that on Monday, institutions reduce their trading more, in percentage terms, than do individual investors. For example, for the whole sample Monday

Table 4. Day-of-the-Week Variations in Trading Volume by Institutions

For each trading day, the volume of institutional trades on each stock is scaled by the 2000 total volume of trades by institutions on that stock. The following regression equation is estimated for each stock using GMM.

$$
y_{i t}=\mu_{i}+\sum_{j=2}^{5} D_{j} \cdot \mu_{i, j}+\varepsilon_{i t}
$$

where $\varepsilon_{i t}$ is the error term for stock i, $y_{i t}$ is the scaled institutional trading volume on each day t, and the $D_{j}$ is the day of the week dummy. $* * *, * *, *$ are the significant level of $1 \%, 5 \%$ and $10 \%$, respectively.

\begin{tabular}{|c|c|c|c|c|c|}
\hline Day-of-the-Week & & $\begin{array}{l}\text { Lowest } \\
\text { Market } \\
\text { Capitalization }\end{array}$ & $\begin{array}{l}\text { Medium } \\
\text { Market } \\
\text { Capitalization }\end{array}$ & $\begin{array}{l}\text { Highest } \\
\text { Market } \\
\text { Capitalization }\end{array}$ & All 300 stocks \\
\hline \multirow[t]{2}{*}{ Tuesday Coefficient } & Average $\left(* 10^{4}\right)$ & $3.261 * * *$ & $2.671 * * *$ & $5.293 * * *$ & 3.742 \\
\hline & Positive Number & 65 & 86 & 91 & 242 \\
\hline \multirow[t]{2}{*}{ Wednesday Coefficient } & Average $\left(* 10^{4}\right)$ & $4.201 * * *$ & $3.282 * * *$ & $2.679 * * *$ & $3.387 * * *$ \\
\hline & Positive Number & 86 & 72 & 87 & 245 \\
\hline \multirow[t]{2}{*}{ Thursday Coefficient } & Average $\left(* 10^{4}\right)$ & $4.251^{* * *}$ & $3.502 * * *$ & $6.287 * * *$ & $4.680 * * *$ \\
\hline & Positive Number & 80 & 75 & 92 & 247 \\
\hline \multirow[t]{2}{*}{ Friday Coefficient } & Average $\left(* 10^{4}\right)$ & $0.758^{*}$ & $0.897 * *$ & $2.814 * * *$ & $1.491 * * *$ \\
\hline & Positive Number & 58 & 77 & 95 & 230 \\
\hline
\end{tabular}


trading by individual investors is $0.0169 \%$ lower than their activities on Tuesday while the difference for institutions is $0.0374 \%$. Similarly, the difference number between Wednesday and Monday is $0.0140 \%$ and $0.0339 \%$ for individuals and institutions, respectively. It is consistent with our argument that the relative increase in proportional trading activities by individual investors on Monday is not caused by an increase in their absolute trading volume but rather by a larger reduction in trading by institutional investors.

\section{Conclusions}

The literature has documented a day-of-the-week phenomenon in which trading activity on Monday is significantly lower than on other business days. A number of studies have investigated this day-of-the-week variation by examining the trading behavior of either institutions or individuals in isolation. In this study, we attempt to fill a gap in the literature by simultaneously examining the trading behavior of both institutional and individual investors. Our results shed light on the role each type of investor plays in this trading anomaly. A reviewer suggested the importance of expanding the timeframe of the data beyond the single year analyzed. We agree, and suggest this for future research.

Consistent with the literature, we find that the proportion of trading volume by individual investors increases on Monday. However, when we examine the absolute trading activities by individual investors, we find that their trading on Monday is actually significantly less than other day of the week. Hence, we hypothesize that the relative increase in proportional trading by individual investors documented on Monday may be caused by a significant drop in the absolute level of trading by institutions. Consistent with our hypothesis, when examining trading by institutions alone, we find that relative to other weekday, on Monday institutions reduce their trading by a large percentage than that by individual. In general, our findings support the hypothesis that uneven trading pattern of institutions is the main factor behind the day-of-the-week agent variation phenomenon.

\section{References}

Abraham, Abraham and David Ikenberry 1994, The Individual Investor and the Weekend Effect, Journal of Financial and Quantitative Analysis 29, 263-277.

Aykol, Ali C., 2011, Stock Returns Around Nontrading Periods: Evidence from an Emerging Market, 21, 20, 1549-1560.

Berument, Hakan and Kiymaz, Halil, 2001, The Day of the Week Effect on Stock Market Volatility, Journal of Economics and Finance, 25, 2, 181-193.

Chan, S.H., Leung,W.K. and K. Wang, 2004, The Impact of Institutional Investors on the Monday Seasonal, Journal of Business 77, 697-986.

Chen, Honghui and Singal, Vijay, 2003, Role of Speculative Short Sales in Price Formation: The Case of the Weekend effect, LVIII, 2, 685-705.

Dicle, M. F. and Levendis, J.D., 2012, The Day-of-the-Week Effect Revisited: International Evidence, Journal of Economics and Finance, 1-31.

Foster, F. Douglas and S. Viswanathan, 1990, A Theory of the Interday Variations in Volume, Variance, and Trading Costs in Security Markets, Review of Financial Studies 3(4), 593-624.

Foster, F. Douglas and S. Viswanathan, 1993, Variations in Trading Volume, Return Variability, and Trading Costs, Evidence on Recent Price Formation Models, Journal of Finance 48, 187-211.

French, Kenneth R., Stock Returns and the Weekend Effect, 1980, Journal of Financial Economics 8, 55-69.

Gibbons, M.R. and P. Hess, 1981, Day of the Week Effects and Asset Returns, Journal of Business 54, 579-596.

Gibbons, M., and J. Shanken, 1987, Sub-period aggregation and the power of multivariate tests of portfolio efficiency, Journal of Financial Economics 19, 389-394.

Keim, Donald B. and Robert F. Stambaugh, 1984, A Further Investigation of the Weekend Effect in Stock Returns, Journal of Finance 39, 819-835.

Lakonishok, J. and Edwin Maberly, 1990, The Weekend Effect: Trading Patterns of Individual and Institutional Investors, Journal of Finance 45, 231-243.

Lakonishok, Josef and M. Levi, 1982, Weekend Effects in Stock Returns: A Note, Journal of Finance 37, 883-889.

Lee, Charles M. C. and Mark Ready, 1991, Inferring Trade Direction from Intradaily Data, Journal of Finance 46, 733-746.

Lee, Charles M.C., 1992, Earnings News and Individual Traders, an Intraday Analysis, Journal of Accounting and Economics 15, 265-302.

Linden, M. and Louhelainen, M., 2006, Testing for Weekday Anomaly in International Stock Index Returns with Non-normal Errors, Applied Financial Economics Letters, 2, 3, 193-197.

Newey, Whitney K., and Kenneth D. West, 1987, A Simple, Positive Semi-Definite, heteroskedasticity and Autocorrelation Consistent Covariance Matrix, Econometrica 55(3), 703-708.

Rogalski, R., 1984, New Findings Regarding Day-of-the-Week Returns over the Trading and Non-Trading Periods: A Note, Journal of Finance 39, 1603-1614.

Sias, Richard W., and Laura T. Starks, 1995, The Day-of-the-Week Anomaly: The Role of Institutional Investors, Financial Analysts Journal 51, May-June, 58-67.

Venezia, Itzhak and Shapira, Zur, 2007, On the Behavioral Differences Between Professional and Amateur Investors After the Weekend, Journal of Banking and Finance, 31, 5, 1417-1426. 